\title{
El gendarme en el umbral: enfoques y debates sobre la burocracia sindical en el kirchnerismo
}

\author{
Paula Varela \\ UBA-CONICET - paula.varela.ips@gmail.com
}

La burocracia sindical ha sido un objeto de debate recurrente en Argentina. Su explicación reside en dos fenómenos que distinguen a nuestro país de otros de la región: su fuerte movimiento obrero y la política de estatalización de esta fortaleza con el peronismo a mitad del siglo XX. Movimiento obrero, peronismo y burocracia sindical se transformaron así en objetos académicos para unos, avatares políticos para otros, o ambas cosas para unos terceros, pero para todos en problemas que dificilmente pueden pensarse en forma separada. Esa tríada ha parido destacados debates de la sociología local como el de los orígenes del peronismo, la llamada "doble conciencia", las formas y tensiones de la organización en el lugar de trabajo, la insistencia de la "anomalía argentina" y, también, el del papel de las izquierdas revolucionarias en la construcción de la clase obrera local. La intensidad con que se indagó sobre estos temas varía según la forma y la fuerza con que el movimiento obrero ha irrumpido en la escena política nacional en diversos momentos específicos.

La última década no ha sido una excepción a esta regla. En este artículo presentamos críticamente los puntos de vista predominantes sobre la burocracia sindical durante el kirchnerismo con el propósito de comprender algunas particularidades de este período.

\section{La incomodidad del objeto}

El modo de pensar el problema (teórico y político) de la burocracia sindical en la última década resulta indisociable de las particularidades del "retorno" del movimiento obrero a la escena política nacional: con la fuerza suficiente como para echar por tierra las teorias del fin del trabajo (y sus colaterales), pero con la debilidad suficiente como para no poder imponer la pregunta sobre la clase obrera como sujeto politico en una intelectualidad reacia de por sí a esa pregunta (más aún en una 
academia enredada en su propia mercantilización). En esa debilidad reside, en parte, la explicación de que el debate sobre la burocracia sindical se haya dado de forma tímida y la mayoría de las veces lateral ${ }^{1}$ a otros debates centrados en las contradicciones de un "nuevo movimiento obrero" que por un lado arrastra fragmentación y precarización de la década del 90 y por el otro irrumpe con la impronta de la crisis del neoliberalismo y los acontecimientos político-sociales de inicios de 2000. En este contexto, los lugares centrales fueron ocupados por los análisis de la conflictividad laboral, la negociación colectiva, la organización de base e incluso el "modelo sindical". Fue entre ellos que se inmiscuyó el problema de la burocracia sindical como un objeto incómodo cuya forma de ser pensado tiene los rastros de esa incomodidad.

Pese a esto pueden reconstruirse tres abordajes que resulta interesante analizar porque implican miradas teóricas distintas y, más allá de las inscripciones politicas individuales de quienes los sostienen, respuestas politicas diferentes.

\section{Las compensaciones y el fetichismo del "poder asociacional"}

El primero es el que podemos denominar, sin temor a deformar perspectivas, como una reivindicación de la burocracia sindical bajo la forma de sostener que gracias a que las cúpulas sindicales negociaron la preservación del denominado "poder asociacional" durante el menemismo es que pudieron retornar como organizaciones fuertes durante el kirchnerismo. ${ }^{2}$ Con el concepto de poder asociacional se hace referencia al conjunto de instituciones que favorecen la posición de los sindicatos para negociar: monopolio de la representación otorgado por el Estado, marco de negociaciones colectivas que protege a los líderes nacionales a expensas de los locales o por fábrica, manejo de los recursos de las obras sociales, subsidios de los empleadores a los sindicatos en el marco de los convenios colectivos de trabajo, contribuciones obligatorias a los sindicatos de los trabajadores cubiertos por el convenio colectivo. Es decir, el conjunto de recursos políticos y sobre todo económicos que fortalecen la posición del sindicato como institución de negociación con el Estado y con las empresas. Llevando hasta el final la idea de que cualquier sindicato es siempre mejor que ningún sindicato, la lógica

1. Una excepción es el dossier "Hacia un debate sobre la "burocracia sindical" en la revista Nuevo Topo $n^{\circ} 7$ (2010), a partir del cual se organizó una charla en el Instituto de Pensamiento Socialista "Karl Marx" con la presencia de varios de los autores, véase: $h t t p: / / w w w . d a i l y m o t i o n . c o m / v i d e o / x f x h O i \_h e r n a n-c a m a r e r o \_c r e a t i o n$.

2. La mejor presentación de esta tesis la encontramos en Etchmendy y Collier (2008). 
argumental reside en afirmar que la denominada "revitalización sindical" de los últimos años no hubiera sido posible sin la colaboración negociada de la burocracia en los 90, y que, en ese sentido, ésta debe ser interpretada como beneficiosa en última instancia para la clase obrera. El colaboracionismo de los 90 es leído, así, como una táctica "defensiva" de las corporaciones sindicales que, astucia de la burocracia mediante, permitió el "regreso del gigante" cuando la ola neoliberal hubo pasado.

La primera contradicción de esta perspectiva aparece en forma inmediata en la medida en que los mismos actores que son señalados como protagonistas de la táctica defensiva son señalados también como destacamento avanzado de la ofensiva neoliberal en Argentina: "Durante la década de 1990, los líderes de los principales sindicatos lograron preservar el poder asociacional al costo de permitir (si no fomentar) los despidos masivos y reducciones de personal" (Etchemendy y Collier, 2008: 188).

La confusión entre defensores y verdugos deriva de una cierta amalgama entre los sindicatos como institución y los trabajadores como clase (problema propio de las visiones institucionalistas de la ciencia politica). ${ }^{3}$ Para intentar salvar las consecuencias de esta confusión el razonamiento es el siguiente: para los quedaron fuera de la representación sindical (desocupados e informales) el colaboracionismo significó debilitamiento sin las compensaciones del Estado (seguro de desempleo, planes sociales, políticas asistenciales); para los que quedaron dentro (40\% de la Población Económicamente Activa-PEA-), significó un fortalecimiento. Un ejemplo ilustrativo del razonamiento es la interpretación de la disminución de los aportes patronales al sistema de seguridad social en 1995. En esa oportunidad, la CGT llamó a dos paros nacionales en oposición a la medida porque ésta reducía el aporte patronal a las obras sociales.

Finalmente, el gobierno y la CGT acordaron mantener la reducción en todas las contribuciones empresarias a la seguridad social, excepto aquellas destinadas a las obras sociales de los sindicatos. El impuesto al empleador que se destina a la caja de los sindicatos se redujo en un $16 \%$, mientras que la contribución empresarial al fondo de seguro de desempleo bajó un 52\%. En resumen, el gobierno eligió a los sindicatos por sobre los desempleados. Este ejemplo es consistente con el resultado global de la reforma laboral en la Argentina neoliberal: una baja desregulación laboral para aquellos trabajadores

3. Etchemendy critica las visiones institucionalistas clásicas sobre los sindicatos en los 90 por subvaluar las negociaciones entre sindicatos y Estado, y su importancia en la resultante institucional. Sin embargo, su posición se enmarca en esta corriente general aunque presente matices (Etchemendy, 2001). 
empleados, y altos costos sociales para los desocupados y para los trabajadores desorganizados de la economía en negro. (Etchemendy, 2004: 157)

Quisiera reparar brevemente en esta concepción de ganadores y perdedores, no sólo porque presenta problemas empíricos al hablar de "baja desregulación laboral" " sino porque hace de lleno a la discusión de la burocracia sindical. El reconocimiento del mantenimiento de recursos propios (con el sugerente nombre de "compensaciones") a cambio de la fragmentación de los trabajadores entre un sector cada vez menor de "cubiertos" por los derechos laborales y otro sector sin esta cobertura no podria ser una expresión más literal de la definición clásica de burocracia sindical como casta con intereses propios. Los defensores del sistema de compensaciones podrian cuestionar que no importa si son o no "intereses propios" de la burocracia sindical (terreno en el que no se meten) en la medida que para ese 40 por ciento que quedó "dentro" del sector formal, la preservación del poder asociacional fue crucialmente importante. Pero ese razonamiento demuestra una incomprensión del papel que juega la fragmentación de la clase obrera en el debilitamiento del conjunto de los trabajadores, incluso de ese 40 por ciento. La burocracia no solo negoció desocupación a cambio de asignación directa de renta, lo que abrió la puerta al fenómeno novedoso de un sindicalismo empresario (participación en las privatizaciones, fondos extra para la transformación de las obras sociales en empresas de salud privada, ingreso al negocio de las AFJP y ART, etc.), sino que fue la desocupación masiva la que permitió la posterior negociación de dos nuevas reformas: la degradación de las condiciones de compra y venta de la fuerza de trabajo (contratos temporales y tercerización) que se dispararon

4. Esta apreciación se basa en un trabajo comparativo sobre el que Etchmendy afirma: "El análisis comparado de los casos de Chile (1973-1989), Argentina (1989-1999) y España (1982-1996) revela que cuanto mayor es la inclusión de las organizaciones sindicales en el proceso de diseño de políticas, menor es el alcance de la reforma del sistema tradicional de relaciones laborales" (2004: 135). La comparación presenta, al menos, dos problemas: el primero, el problema metodológico de la construcción de los datos provistos por los institutos de cada país que vuelve dificil establecer si permiten o no la comparabilidad. El segundo, y más importante, es que al ser una comparación sincrónica no tiene en cuenta los procesos históricos a través de los cuales cada uno de esos movimientos obreros nacionales llega al momento de las reformas. Esa subvaluación del peso de la lucha de clases (y sus resultados) en el análisis, hace que la comparación se vuelva más un ejercicio politológico que un esquema explicativo. Por último, la hipótesis (no expresa) que sobrevuela el argumento es la de que las contrarreformas en Argentina "podrian haber sido peores". Sin negar esa posibilidad, resulta un presupuesto incontrastable que termina operando como validación ideológica de la propia hipótesis. 
exponencialmente luego de la reforma laboral de 1994 (pactada con los sindicatos); y la precarización de las condiciones de consumo productivo de la fuerza de trabajo habilitando convenios colectivos por empresa o incluso por sector aunque se mantuviera formalmente la ultractividad.

Este conjunto de medidas negociadas perfora las fronteras entre "ganadores" y "perdedores" y transforma a todos en perdedores (aunque en su interior puedan diferenciarse sectores), modificando una de las mayores fortalezas del movimiento obrero en Argentina: su relativa homogeneidad. La fragmentación negociada por etapas redunda en un perjuicio para el conjunto de la clase obrera, incluso para el $40 \%$ que en estas perspectivas componen el sector de "ganadores". La no comprensión de este fenómeno lleva a Etchemendy a encontrar una paradoja que no puede explicar: el hecho de que, en su argumentación, las reformas en Argentina hayan sido parciales gracias a la colaboración de los sindicatos, pero para el establishment de la ciencia política (y de los organismos internacionales con quienes comparten personal) el caso argentino haya sido un modelo internacional de aplicación de contrarreformas neoliberales. La paradoja se disuelve al observar que la negociación de la burocracia sindical de preservación de recursos propios a cambio del mantenimiento de poder asociacional no sólo no niega el éxito de las contrarreformas sino que presenta un "modelo" de su obtención a través de la fragmentación (y debilitamiento) de la clase obrera en su conjunto.

Es esa dinámica de la década del 90 lo que explica dos particularidades del "retorno de los sindicatos" a la escena politica durante el kirchnerismo que aparecen, desde estas perspectivas, como fenómenos de dificil comprensión. La primera, la contradicción entre la definición de "retorno del gigante" ${ }^{5} \mathrm{y}$, al mismo tiempo, la afirmación del carácter segmentado del neocorporativismo kirchnerista. No son fenómenos compatibles. Las características de lo que Juan Carlos Torre definió como "gigante invertebrado" se asentaban en la relativa homogeneidad del movimiento obrero (tanto en el mercado de trabajo como en su identificación con el peronismo). Es esa homogeneidad la que el colaboracionismo de la burocracia sindical hizo estallar por los aires en los 90 vehiculizando la fragmentación. En estas condiciones, la ilusión del "retorno del gigante" o bien obliga a criticar ese colaboracionismo y buscar las estrategias de "re-homogeneización" del movimiento obrero (lo que implica necesariamente enfrentarse a la burocracia sindical que opera de garante de la fragmentación), o bien se manifiesta como

5. Etchemendy (2011) titula "El retorno de un gigante" un análisis sobre la revitalización sindical durante el kirchnerismo en abierta alusión al "gigante invertebrado" de Juan Carlos Torre. 
un deseo de retorno de la homogeneidad ideológica (peronista) sin su homogeneidad social. De esta misma contradicción emerge el segundo fenómeno que aparece sin explicación: el desfasaje entre el nuevo protagonismo de los sindicatos y la ausencia de su traducción al interior del Partido Justicialista. Más allá de los intentos de argumentar ese desfasaje por necedades políticas del gobierno de Cristina Fernández (que sin duda las hubo), la base material de esa imposibilidad reside en las consecuencias de la política de fragmentación de la clase obrera en los 90 (politica que fue continuada durante el kirchnerismo por los mismos sectores que enuncian su deseo de volver al esquema de tres tercios en el PJ). ${ }^{6}$ El desplazamiento del sector sindical por el territorial que analiza Steven Levitsky en su estudio del Partido Justicialista es una expresión de las modificaciones que introdujo el neoliberalismo (ayuda de la burocracia sindical mediante) al interior de la propia clase obrera. Para decirlo en términos de Etchemendy, es la expresión de la existencia y el peso social de los "perdedores" que quedaron fuera de la representación sindical y arrojados al territorio (y sus sistemas de representación estatalizada). Para seguir con la metáfora de Torre: no hay restitución del 33\% dentro del peronismo sin "gigante" dentro del sindicalismo.

En sintesis, la mirada de la reivindicación de la burocracia sindical termina enfrentándose a las consecuencias de la politica de colaboración negociada de los 90 como límite a su propia ilusión peronista.

\section{Procedimiento versus politica}

El segundo abordaje es el que define burocracia sindical por oposición a democracia, refiriendo tanto a la democracia al interior de las organizaciones sindicales (democratización de la relación entre bases y dirigentes) como a la que opera hacia afuera (democratización de la afiliación o descorporativización de los sindicatos). Sin tener una fuerte presencia en los estudios empíricos sobre los sindicatos en la última década (a diferencia del abordaje anterior), esta perspectiva es parte de los debates académicos y políticos a través de la influencia de las teorías del sindicalismo de movimiento social $(\mathrm{SMS})^{7}$ que la CTA recupera

6. Como señala Levitsky (2005), el tercio sindical tiene sus orígenes en la noción corporativista de que los dirigentes sindicales tenían derecho a cierto número de candidaturas partidarias y puestos de conducción.

7. Las experiencias que suelen presentarse como "modelo" del sindicalismo de movimiento social (SMS) son la CUT brasileña y la COSATU sudafricana. Algunos de los elementos del SMS pueden rastrearse en la declaración de Burzaco de formación de la CTA en 1993. 
como referencia. ${ }^{8}$ Esta propuesta de sindicalismo alternativo intentó ser una respuesta, desde el punto de vista de los movimientos sociales, a las tesis de la "preservación institucional" como reivindicación (más o menos abierta) al sindicalismo empresario o de concertación durante el neoliberalismo. En este sentido, tiene la virtud de haber puesto sobre la mesa una agenda de discusión en la que la burocracia sindical (obturada como problema y transformada en virtud en la visión anterior) volvía a problematizarse como parte del debilitamiento de los sindicatos y no como parte de su "salvación". Sin embargo, la definición del concepto de burocracia por oposición al de democracia redunda en una suerte de fetichismo del procedimiento que encierra el problema en el debate de mecanismos formales, tanto internos como externos, produciendo una escisión entre los problemas organizativos y los problemas politicos, particularmente lo que hace a la relación de las organizaciones sindicales con el Estado y con las patronales.

Esta escisión puede verse, en el caso de la CTA, en el reclamo de "libertad sindical" en el que el problema de autonomía respecto del Estado (debate histórico para las organizaciones sindicales) termina reducido a una versión legal-procedimental concentrada en la lucha contra el unicato, ${ }^{9}$ es decir, por el reconocimiento legal de la central y la pluralidad de sindicatos por rama y por empresa. Esta identificación entre "sindicatos legalmente libres" y "sindicatos independientes" no expresa solamente un problema teórico (en la medida en que la estructura sindical legal es una expresión de la estatización pero no la explica en su conjunto), sino un problema político que en la Argentina postconvertibilidad tomó valores concretos. La negativa del gobierno kirchnerista de otorgar la personería gremial a la CTA produjo dos efectos. Por un lado, paralizó a la central, llevándola a un callejón sin salida que puso de manifiesto la paradoja de una central obrera que, habiendo nacido de la crítica a la CGT como burocracia estatalizada, terminó transformando el reconocimiento estatal como la principal batalla politica propia. Por otro, visibilizó, a partir de la ruptura y la transformación de la CTA Yasky en central gubernamental, que la independencia respecto del Estado (y del partido de gobierno) se juega en el terreno de la estrategia política de la organización obrera y no en el terreno de los procedimientos organizativo-legales.

Pero a su vez, es esta misma escisión entre procedimientos (demo-

8. Para un recorrido por el impacto de este debate en las ciencias sociales locales, véase Ferrero y Gurrera (2007), Senén González y Haidar (2009), Senén González y Del Bono (2013).

9. La Ley de Asociaciones Profesionales en Argentina establece que será reconocido y habilitado por el Estado un solo sindicato por rama de actividad. 
cracia) y orientaciones políticas (posicionamientos respecto del Estado y los empresarios) la que afecta directamente la denominada "democratización interna", ${ }^{10}$ alentando prácticas similares a las que el SMS vino a combatir. Una expresión de esto han sido las elecciones de 2010 en las que las acusaciones de fraude, manipulación de padrones, connivencia con el Ministerio de Trabajo e incluso existencia de patotas, terminó colapsando la elección. Pero también pudo observarse en uno de los dos sindicatos industriales que pertenecen a la CTA, el SUTNA. El surgimiento de un proceso de organización y lucha a nivel de fábrica en FATE (que inauguró el sindicalismo de base fabril en la zona norte del Conurbano bonaerense en 2007) puso de manifiesto las mismas características corporativas y burocráticas que se repetirian luego en otros procesos en fábricas de la zona pertenecientes a la CGT: la existencia de lo que denominamos "punteros fabriles" como reemplazo de la organización de fábrica, el ataque por parte de la dirección sindical a la organización de base, los mecanismos fraudulentos en las elecciones sindicales, los arreglos con la patronal para el despido de activistas. ${ }^{11}$

A esto se suma un problema que se vuelve central a la hora de pensar la "democratización externa" a través de la afiliación: la forma en que conceptualizan las alianzas del movimiento obrero con otros sectores sociales a los fines de fortalecer el movimiento "desde abajo". Esta alianza, dirigida a borrar los rasgos corporativos del sindicalismo clásico y con ellos la fragmentación que el corporativismo comporta, está concebida como una articulación entre colectivos (movimientos de desocupados, territoriales, inmigrantes, étnicos, género, etc) como si todas las partes ocuparan posiciones sociales equivalentes en el capitalismo que pueden agregarse voluntariamente. ${ }^{12}$ Esto lleva a la teoria (y al programa)

10. Acorde con la escisión que estamos señalando en las teorias de SMS, en los debates académicos los problemas de organización y democracia interna de las organizaciones sindicales suelen abordarse en forma separada de las relaciones entre los sindicatos y el Estado. En sentido inverso, ya en 1940, Trotsky señalaba la relación intrínseca entre independencia politica del Estado y democracia: "La consigna esencial en esta lucha es: independencia completa e incondicional de los sindicatos respecto del Estado capitalista. (...). La segunda consigna es: democracia sindical. Esta segunda consigna se desprende directamente de la primera y presupone para su realización la independencia total de los sindicatos del Estado imperialista o colonial" (Trotsky, 2010: 128)

11. Para un análisis de ese proceso y su relación con el sindicalismo de base, véase La disputa por la dignidad obrera, Varela, 2015.

12. Es importante señalar que la igualación entre movimiento obrero y otros movimientos sociales es más bien un producto del desarrollo de las teorías de SMS que de su formulación original en Kim Moody (aunque alli se encuentre inscripto). Moody destaca la "mayor fortaleza" de los trabajadores organizados pero esta fortaleza parece morderse la cola al buscar su sustento en la propia organización: "El sindicalismo de movimiento social implica una orientación estratégica activa que utiliza lo oprimido 
a otro callejón sin salida que resulta de la siguiente pregunta: ¿la articulación es producto de la pura voluntad subjetiva entre las partes o tiene puntos de apoyo objetivos? Esta encrucijada teórica irresuelta ha abierto la puerta a interpretaciones de la teoría de sindicalismo de movimiento social en la que toda noción de clase trabajadora o de trabajadores se disuelve en la noción de "ciudadanos" a partir de la cual la articulación ya no es entre colectivos de clase o colectivos sociales, sino directamente entre individuos. La CTA muestra este problema a través de la articulación entre sus sectores internos. Si bien la central recibe la afiliación de movimientos de desocupados al mismo nivel que de colectivos de asalariados (y de individuos) eso no ha evitado el corporativismo como estrategia política. Más aún, un doble corporativismo, el de los desocupados (con su agenda y dinámica de demandas) y el de los asalariados (con la suya). ${ }^{13}$ La confluencia ha sido más bien formal que en tanto constitución de fuerza social. En los momentos en que esta confluencia ha significado una unidad de distintas fracciones de los trabajadores, ha sido con la crisis de la convertibilidad que empujó a la articulación coyuntural de luchas sociales también a sectores de la CGT, como el MTA, que no sólo no sostienen un programa de SMS sino que son su mayor oposición.

\section{Revisiones sobre la burocracia y la conciencia}

El tercer abordaje es el que posa la mirada sobre los procesos de lucha y organización de los trabajadores para preguntarse sobre las posibilidades de que esas experiencias encierren (o no) una renovación de las organizaciones de los trabajadores, pero sobre todo, una renovación de la estrategia de la clase obrera. En este camino, este enfoque intenta una tesis revisionista sobre la burocracia sindical que pone el foco en la relación entre bases y cúpulas, pero no desde la perspectiva de la

con más fuerza de la sociedad, generalmente los trabajadores organizados, para organizar a aquellos que son menos capaces de sostener una automovilización: el pobre, el desempleado, los trabajadores informales, las organizaciones barriales" (citado en Ferrero y Gurrera, 2007: 109). En cierta medida, el SMS es, al mismo tiempo, una reacción a la crisis de los sindicatos bajo la reflexión de los límites del sindicalismo burocratizado, al tiempo que la aceptación de la pérdida de centralidad de la clase obrera y por ende de los límites de su potencialidad. Eso termina operando como profecía autocumplida de la imposibilidad de revitalización sindical.

13. En este punto, recorriendo un camino diferente, llega a un lugar similar de "naturalización" de las divisiones de la clase obrera al que llega Etchmendy en el que las divisiones entre asalariados, precarizados, desempleados, deben ser "resueltas" a través de distintas relaciones con el Estado, es decir, distinto tipo de demandas: salariales unos, asistenciales los otros. 
democracia procedimental, sino desde la pregunta acerca de por qué los trabajadores apoyan a los burócratas. Dentro del campo del marxismo y en debate contra la caricaturización de teorias que considerarian que la burocracia presenta una completa independencia respecto de su base, estas visiones intentan reflexionar sobre la relación entre los dos polos a partir de colocar en el centro el análisis del proceso de burocratización y de la conciencia obrera como factores explicativos de la burocracia sindical. Así, la burocracia sindical pasa a ser el fenómeno que debe ser explicado, y deja de ser un fenómeno explicativo de determinados procesos sociales.

En cuanto al proceso de burocratización (para lo que suele ser una referencia ineludible el Hyman de Relaciones industriales [Hyman, 1981] y su descripción de la burocratización de los delegados de base) el hincapié está puesto en el muy estudiado problema de la diferenciación técnica (y luego social) al que están sometidos los liderazgos en las organizaciones de masas en el capitalismo. En cuanto al problema de la conciencia, los argumentos suelen resaltar que es el propio nivel de la conciencia de los obreros el que explica (a través del apoyo politico o la pasividad) la existencia de la burocracia. Esto último lleva a la pregunta obligada de cómo se desarrolla o se conforma esa conciencia a partir de la cual los obreros apoyan o, al menos, son pasivos ante la burocracia sindical. Ante esta pregunta, hay dos tipos de respuestas en esta perspectiva. Una en la que la conciencia se determina en forma externa y a priori a esa burocracia restituyendo la independencia entre las bases y las cúpulas pero esta vez para afirmar que las cúpulas son expresión de las bases. Este argumento se construye en espejo de la visión que, en principio, venía a rebatir (la de la clase obrera ontológicamente revolucionaria) para establecer una clase obrera que resulta ontológicamente pro-burocracia (o reformista). ${ }^{14}$ La otra respuesta a esta pregunta reside en considerar que la conciencia obrera se conforma en el cruce de múltiples mecanismos a través de los cuales se configuran los intereses inmediatos de los trabajadores, entre los cuales la burocracia sindical es uno de ellos que no constituye un objeto en sí mismo. Bajo la

14. Este tipo de respuestas puede encontrarse en Nicolás Iñigo Carrera: "A mí me parece que mucho más interesante que la lucha antiburocrática, seria plantearse el problema de la conciencia de esas bases. Qué se hace, por qué se hace, pero obviamente no es suficiente. Qué se hace para construir conciencia, otra conciencia en los trabajadores. Y entonces la caída de esas burocracias es algo que viene por añadidura" (Scodeller y Ghigliani, 2010: 124). Aquí, la conciencia obrera se construye por fuera de la relación con la burocracia y es a partir de esa construcción que la burocracia "cae por añadidura". En Archivos n 6 (Varela, 2015b) hemos realizado un debate con Iñigo Carrera que, si bien no se centra en el problema de la burocracia sindical, toca tópicos que hacen a las perspectivas sobre la conciencia obrera. 
irreprochable consigna de "complejizar" el análisis, la propuesta termina en una licuación del problema de la burocracia sindical negando (en el debate intelectual, el análisis empírico y también la discusión política), su especificidad y por ende, su interés. ${ }^{15}$ En ambos casos, la burocracia termina siendo un "mal necesario" de una clase obrera cuya conciencia (reformista) se constituye más allá de la existencia de esa burocracia. ${ }^{16}$

Quisiera señalar tres desplazamientos teóricos que implica esta tercera perspectiva (tanto en su versión esencialista como en la constructivista). En primer lugar, la confusión entre el proceso de burocratización y la consumación de una burocracia sindical consolidada (confusión presente también en Hyman). Como ha sido ampliamente debatido en el marxismo, la diferenciación técnica es un proceso necesario para comprender la generación de una burocracia pero no es suficiente. ${ }^{17}$ Es la inscripción de esta diferenciación en el proceso de estatización de las organizaciones sindicales ${ }^{18}$ la que produce un salto cualitativo que permite hablar ya no de un proceso (para el que el propio movimiento obrero habia desarrollado anticuerpos desde mitad del siglo XIX en adelante) ${ }^{19}$ sino de una burocracia consolidada en la medida en que es la relación con el Estado moderno burgués (y sus necesidades de institucionalización-regimentación de las organizaciones de masas de

15. Este tipo de respuesta puede encontrarse en Pablo Ghigliani. Si bien, tiene la virtud de considerar que la burocracia es parte de la experiencia que conforma la conciencia obrera, ese carácter "activo" de la burocracia se pierde al fundirla en un abstracto "modo colectivo de organización y definición de intereses". Véase Ghigliani y Belkin (2010).

16. Es esta idea de inevitabilidad de la burocracia sindical la que abre puntos de contacto entre esta posición y la primera, en la medida en que, ante el hecho inevitable de esa burocracia necesaria (dado el carácter reformista del "momento" y de la conciencia obrera), la discusión pasa a ser de qué manera se negocia mejor o peor con el Estado y con las patronales, según los momentos de crisis, los marcos de oportunidades, etc. La conservación del "poder asociacional" al que refiere Etchmendy se convierte en un ejemplo de una "buena negociación" en un contexto adverso.

17. Un muy buen escrito (y completamente ignorado en la academia) respecto de la combinación entre diferenciación técnica y social (pensado para explicar la burocracia de la URSS) es el de Christian Rakovsky, "Los peligros profesionales del poder" (1928). Para una teoría diferenciada de la burocracia en las organizaciones obreras, véase Mandel (1994).

18. Es por ello que, como decíamos al inicio del artículo, la tríada entre movimiento obrero, peronismo y burocracia sindical es indisociable. Si bien antes del peronismo pueden observarse procesos de burocratización en diversos sindicatos, esos procesos no alcanzan para establecer la existencia de una burocracia sindical consolidada (aunque la faciliten posteriormente).

19. El primer programa de combate a la burocracia (estatal) a gran escala es el de la Comuna de París. 
clase obrera) la que transforma a esa capa de dirigentes en agentes de ese disciplinamiento. Sin este componente, la burocracia aparece como el resultado de una pura presión técnica disociada de las instituciones de dominación burguesa y su papel como agente de dominación resulta inaprehensible. Gramsci (quien, junto con Trotsky, fue el marxista que más y mejor analizó los cambios en los Estados de Occidente y el papel de los partidos y sindicatos obreros en dichos cambios) repara especialmente en esta relación y define a la burocracia sindical como la "policía política" del movimiento obrero, aludiendo al proceso de extensión de los mecanismos (coercitivos y consensuales) de la dominación del Estado en el seno de la "sociedad civil". ${ }^{20}$ Más aún, incorpora una tercera dimensión en el análisis de la sofisticación de los mecanismos de dominación del Estado "ampliado" que adquiere plena actualidad a la luz de los derroteros de la burocracia en la década del 90: la corrupción como "alma permanente" de la burocracia. Dice Gramsci:

Entre el consenso y la fuerza está la corrupción-fraude (que es característica de ciertas situaciones de dificil ejercicio de la función hegemónica en que el empleo de la fuerza presenta demasiados peligros), o sea el debilitamiento y la parálisis provocada al antagonista o a los antagonistas acaparándose a sus dirigentes, encubiertamente por lo general, abiertamente en caso de peligro advertido, a fin de sembrar la confusión y el desorden en las filas adversarias. ${ }^{21}$

La des-inscripción de la burocracia sindical del campo de las instituciones de dominación del Estado es la que abre la puerta al segundo

20. Agustín Santella (2014) también retoma los análisis de Gramsci sobre la acción sindical. Su interpretación termina otorgando mayor preeminencia a los elementos "consensuales" (en detrimento de los elementos de "coerción" y "corrupción"), por considerar que éstos son propios de la función de los sindicatos en los marcos de las democracias capitalistas. Sin embargo, es el propio Gramsci el que rompe la "correspondencia" entre sindicatos en Occidente y función reformista al señalar que los elementos consensuales no sólo no niegan el carácter coercitivo y la función del fraude, sino que se combinan con ellos produciendo un "consenso coercitivo". Ya en los escritos de L' Ordine Nuovo denunciaba que "surgió una verdadera casta de funcionarios sindicales y periodistas, con una psicología de grupo particular por completo contraria a la de los obreros", y en sus Cuadernos de la Cárcel desarrolla una teoría más específica sobre la burocracia sindical en la que explica cómo el transformismo sobre un sector proveniente de las clases subalternas produce una casta que oficia de agente para la estatización de los sindicatos (lo que constituye una importante afinidad con los planteos de Trotsky).

21. "El jacobinismo al revés de Charles Maurras", citado en Maiello y Albamonte (2016: 166). 
desplazamiento: la negación del carácter performativo de la burocracia sindical en los procesos de agregación y de desagregación de clases con los que la burguesía es capaz de mantener su dominación. Es decir, la performatividad de la burocracia en la subalternización de la clase obre$r a$, en su configuración como clase subalterna ${ }^{22}$ y lo que esto implica como obstáculo para su constitución como "sujeto peligroso". He alli lo que termina desdibujándose en estas perspectivas de la burocracia sindical, siendo que allí reside la mayor de sus importancias. Cuando se utiliza la tan maltratada metáfora de la burocracia como "losa" no se está haciendo referencia a un techo que oculta la emergencia de una conciencia revolucionaria que "ya está allï" a priori de la experiencia. Se hace referencia al establecimiento en la experiencia (práctica e ideológica) de la clase obrera de un límite (vía coerción, consenso y fraude) a la posibilidad del desarrollo de una conciencia de "sujeto peligroso" o, para usar al propio Gramsci, de una conciencia de la clase obrera como clase hegemónica. Por supuesto que la identificación de la burocracia como obstáculo central es sólo el comienzo del problema (y no su resolución), pero no identificarla en su performatividad abre la puerta a teorias (y estrategias) en las que el debate de cómo forjar una conciencia anticapitalista o revolucionaria va por un lado (ya sea historicista, ya sea idealista), y el debate sobre la burocracia sindical va por otro (o ni siquiera va). ${ }^{23}$ En sentido contrario a esa lógica escindida, el combate a la burocracia sindical es parte necesaria (aunque no suficiente, pero no es esa la discusión de este artículo) del combate para que se despliegue otra estrategia en la clase obrera.

\section{Conclusiones}

Si uno analiza el nuevo protagonismo de los sindicatos durante la década kirchnerista bajo la clave de lectura de la discusión sobre la burocracia sindical, lo que observa es un proceso que combina una clase obrera que se vio fortalecida en términos objetivos (por el crecimiento económico y del empleo) y también en términos subjetivos (por la existencia de una nueva generación de trabajadores marcada por el 2001 como "reapropiación de la política desde abajo"), con una burocracia sindical cuyo fortalecimiento desde el Estado es indisociable de la necesidad de regimentación de esa recomposición de "fuerza moral" ${ }^{24} \mathrm{de}$

22. Para una relación entre el concepto de revolución pasiva en Gramsci y la subalternización, véase Juan Dal Maso, IDZ, 26, diciembre de 2015.

23. Maiello y Albamonte (2016) rastrean en el pensamiento del propio Gramsci el inicio teórico de esta disociación y recuperan comparativamente los desarrollos de Trotsky.

24. Usamos "fuerza moral" para destacar la relación intrínseca entre las percepciones 
la nueva clase obrera. Es en el marco de las contradicciones de este proceso que el sindicalismo de base emergido de 2004 en adelante y la influencia de la izquierda en él adoptan la importancia que tienen: la de desafio al "consenso coercitivo" de la burocracia sindical.

Son estas características especificas las que permiten establecer algunas comparaciones con las formas que asumieron los sindicatos en el menemismo. La denominada "preservación institucional" 25 como mecanismo complementario del avance de la fragmentación del mercado de trabajo y la precarización de las condiciones de explotación introdujo una separación entre la reproducción de la burocracia como tal y la reproducción de la base obrera, que no existía previamente en esa magnitud. Adrián Piva analiza este fenómeno a la luz de la conflictividad laboral de la década del 90 para señalar que existe un "desacople" entre los conflictos económicos y los políticos, producto en última instancia del desacople entre las direcciones sindicales y las bases, que haria que los paros generales sean instrumentos políticos de la burocracia con independencia de las necesidades de los trabajadores. ${ }^{26}$ Aunque no vamos a desarrollar aquí todos los elementos que involucra la discusión, queremos sin embargo plantear que la disociación que tiende a hacer Piva, si bien puede resultar certera para la coyuntura histórica específica que analiza (1996), resulta problemática si intenta transformarse en una conceptualización permanente sobre la relación entre la situación socioeconómica de las bases y la acción política de las cúpulas sindicales. El carácter problemático lo daría que, llevado a su extremo, este argumento implica una suerte de teoría de la independencia absoluta de las cúpulas respecto a las bases obreras, que volvería inútil el concepto de sindicatos y, con él, el de burocracia sindical. La mayor independización entre cúpulas y bases (y la consecuente aparición del sindicalismo empresario como extremo de reproducción de recursos económicos e

que la clase obrera tiene sobre los alcances y límites de su propia acción y la "fuerza material" que esa clase obrera detenta en el enfrentamiento con las clases dominantes. A contramano de cualquier interpretación idealista de fuerza moral, ésta sólo puede medirse a través de los enfrentamientos de clase como fuerza material. Sin embargo, "del hecho de que para comparar dos "fuerzas morales" haya que hacerlo como parte de "fuerzas materiales" no disminuye el peso y la significación de las primeras sino al contrario, las muestra como lo que son, parte integral de la relación de fuerzas en el más estricto sentido del término" (Maiello y Albamonte, 2016: 164).

25. Murillo (1997: 438) denomina "preservación institucional" a la política de "compensar la caída de las cuotas sindicales y contribuciones de obras sociales con ingresos financieros derivados de actividades empresarias".

26. Este análisis es, a su vez, una crítica a las lecturas de Nicolás Iñigo Carrera sobre la conflictividad en la década menemista. Para seguir ese debate, véase Piva (2006) e Iñigo Carrera (2009). Para una lectura de la conflictividad en la década kirchnerista a la luz de este debate, véase Varela (2014). 
institucionales por fuera de la base de representación) ${ }^{27}$ parece más bien asociado a la profundidad de la derrota de la hiperinflación ${ }^{28}$ (y de la desocupación masiva que le siguió), que al inicio de una nueva matriz permanente de relación entre cúpulas y bases. En cierto modo podría definirse ese desacople como una forma sindical de la derrota.

El fortalecimiento de la burocracia sindical en la década kirchnerista tiende a confirmar esta hipótesis en la medida en que combina el mantenimiento de rasgos de desacople heredados de los 90 que expresan el mantenimiento de una clase obrera fragmentada con un fuerte sector de informales y precarizados, con la introducción de rasgos de re-acople basados en la necesidad de disciplinamiento de las expectativas de la nueva generación obrera que ingresó al mercado de trabajo a partir de 2003. En el marco del carácter restauracionista del kirchnerismo en tanto gobierno cuya principal política estatal fue la reconstrucción de las instituciones del régimen que entró en crisis en $2001,{ }^{29}$ la forma que asumió el fortalecimiento de la burocracia sindical estuvo centrada en la recuperación de recursos institucionales volcados casi exclusivamente a la regulación de la puja salarial como "objeto de negociación tutelado" 30 para una base de trabajadores que, si bien ampliada en términos numéricos, no se modificó sustancialmente en términos de su precarización.

27. Las investigaciones sobre sindicalismo empresario, que profundizan en esta independización a través del análisis del salto cualitativo que significa la transformación de los sindicalistas en representantes directos del capital, tienen la fortaleza de presentar más elementos sobre este proceso, pero suelen ser débiles a la hora de establecer las relaciones entre ese salto cualitativo y su impacto en la relación entre cúpulas y bases.

28. Ghigliani (2008) realiza una crítica al uso del concepto de "derrota" por considerar que opera como un término que esconde diferencias de interpretación y explicación de la historia reciente del movimiento obrero. Si bien resulta interesante el ejercicio que realiza en la medida en que identifica perspectivas teórico-políticas diferenciables (aunque no necesariamente bien diferenciadas), consideramos que el concepto de derrota tiene la virtud de expresar de forma sucinta el presupuesto de lucha de clases inscripto en la historia de la clase obrera y la relación entre los resultados de estas luchas y las modificaciones institucionales (elementos ausentes en los análisis predominantes en las ciencias sociales).

29. Sobre el carácter del kirchnerismo como restauración, véase el análisis de Christian Castillo (2011) y el reciente libro de Alberto Bonnet (2016).

30. En los estudios sobre las relaciones laborales durante el kirchnerismo existe acuerdo en sostener que el salario se constituyó en el objeto negociable casi excluyente de las negociaciones colectivas. Esto desplazó la discusión de la flexibilización laboral (tanto interna como externa) constituyendo a la precarización laboral de los 90 como "objeto no negociable". El nivel de precarización laboral puesto hoy de manifiesto ante el ajuste del gobierno de Macri es una expresión de dicho fenómeno. Otra expresión es la importancia que asumieron las condiciones de trabajo (los "rotos") en los procesos de sindicalismo de base. 
Esto no niega la persistencia de formas de fortalecimiento propias de los 90, es decir, "desacopladas" de las relaciones de representación (como las obras sociales y permanencia de participación en los negocios rentables). Por el contrario, lo que vemos es la combinación de ambas formas, combinación coherente con las características de una recomposición social de los trabajadores que se despliega sobre el mantenimiento de las condiciones de explotación conquistadas por la burguesía en los 90 .

Pero dijimos antes que había que observar también otro movimiento durante el período: la existencia de un sindicalismo de base como expresión heterogénea de expectativas obreras en disputa. En el libro publicado el año pasado por la colección Archivos (Varela, 2015a), abordamos las características específicas de este sindicalismo de base en el período. Aquí sólo señalaremos que ese proceso permite observar un elemento central que hace a la discusión de la burocracia sindical y que intentamos exponer más arriba: que la expectativas de los trabajadores (particularmente la nueva generación obrera que ingresó al mercado de trabajo empujada por el crecimiento económico) no están determinadas a priori (ni de una vez para siempre) sino que son ellas mismas terreno de disputa. Como encontramos nosotros en nuestras investigaciones (pero también está presente en estudios tanto del sector servicios como industrial) el sentido de lo "justo" (para usar la expresión de John Ke1ly) y de los horizontes de acción asociados a esa "justicia", no son un hecho dado sino que se construye en la propia experiencia que hacen los trabajadores con la organización sindical. En esa construcción, la burocracia sindical ha sido (y es) un agente activo en el establecimiento de un horizonte de posibilidades en el que la precariedad y la fragmentación formen parte de "lo justo" o al menos, de "lo inevitable". Es decir, en el formateo de una determinada "fuerza moral" de la nueva clase obrera que se constituyó como tal en el kirchnerismo. El establecimiento de techos salariales, el fortalecimiento de fronteras entre trabajadores, la configuración de "objetos no negociables" forman parte del proceso de constitución de la conciencia de esa clase obrera. Cuando en 2013 hicimos una entrevista a distintos dirigentes del SMATA, Manuel Pardo (encargado en ese momento de la formación sindical y ex Secretario Adjunto de la conducción de Rodríguez) se refirió a la Comisión Interna de Lear (opositora y abiertamente antiburocrática) ${ }^{31}$ como un hecho que

31. En noviembre de 2011, se llevan a cabo las elecciones de Comisión Interna en Lear. La dirección del SMATA, cambia el sistema de votación (de voto por persona a voto por lista) para evitar que ganen algunos delegados independientes (como había sucedido previamente, dando como resultado una Comisión Interna "mixta", de oficialistas e independientes). Sin embargo, para sorpresa de la dirección del Smata, con 310 votos sobre 249, gana la Lista Celeste compuesta por militantes del PTS e independientes, conformando una CI abiertamente opositora a la Verde de Pignanelli. 
no podía prosperar en la medida en que contradecía el "sentido común" de los obreros "que saben que si le va bien a la empresa, también le va bien a ellos". Clase de peronismo concentrada, Pardo señalaba que esa CI iba en contra de lo que podríamos llamar "la conciencia media" de los obreros de Lear. Un mes después de esa charla, la CI opositora volvía a ganar las elecciones, esta vez por mayor porcentaje que dos años atrás. Ese triunfo se explica porque los obreros "sabian" que estaban todos "rotos" (para usar la forma en que refieren a las consecuencias de sus propias condiciones de trabajo) y ese saber se constituyó en "sentimiento de injusticia" en la experiencia colectiva de trabajo y organización fabril contra la burocracia sindical, experiencia en la que entraron en juego otros horizontes de posibilidad (algunos de ellos a través de la actividad de militantes de izquierda). Ese escenario no es un exotismo de Lear, es el sustrato sobre el que se desplegó el sindicalismo de base durante el kirchnerismo. Fue necesario pasar abiertamente y brutalmente a politicas de coerción y fraude por parte del SMATA (despidos sin preventivo de crisis, desafuero de delegados en asambleas fuera de estatuto pero cubiertas por el Ministerio de Trabajo, decenas de represiones en la Panamericana y uso de patotas sindicales) para inculcar en los obreros y obreras de Lear esa "conciencia media" buscada. Incluso esa violencia es una muestra de que la conciencia es un terreno en disputa.

\section{Bibliografia}

Andrada, G., M. Cambiasso y J. Longo (2015), "La otra cara de la revitalización sindical", en Ideas de Izquierda, n 20, junio.

Armelino, Martín (2012), "Kind of blue. Las vicisitudes de la Central de Trabajadores de la Argentina (CTA) durante los años kirchneristas", en Germán Pérez y Ana Natalucci (eds.), Vamos las bandas. Organizaciones y militancia kirchnerista, Buenos Aires: Nueva Trilce.

Bonnet, A. (2016), La insurrección como restauración. El kirchnerismo, Buenos Aires: Prometeo.

Castillo, C. (2011), La izquierda frente a la Argentina kirchnerista, Buenos Aires: Planeta.

Dal Maso, J. (2015), "Hegemonía y revolución permanente", en Ideas de Izquierda, $\mathrm{n}^{\circ} 26$.

D’Urso, L. y J. Longo (2015), “Sindicalismo y política: el caso de la autopar-

En 2013 vuelven a ganar las elecciones. En 2014 la empresa origina un conflicto con despidos y el SMATA desafuera a los delegados combativos. Para un análisis del proceso véase Lucila D’Urso y Julieta Longo (2015), y Andrada, Cambiasso y Longo (2015). Para un análisis de la utilización por parte del SMATA de los despidos sin preventivo de crisis, véase Vasallo (2015). 
tista Lear como experiencia de sindicalismo radical en Argentina”, XII Congreso Nacional de Estudios del Trabajo ASET, agosto, Buenos Aires. Etchemendy, S. (2001), "Construir coaliciones reformistas: la política de las compensaciones en el camino argentino hacia la liberalización económica”, Desarrollo Económico, vol. 40, n 160 , enero-marzo.

- (2004), "Represión, exclusión e inclusión: relaciones gobierno-sindicatos y modelos de reforma laboral en economías liberalizadas", Revista SAAP, vol. $2, \mathrm{n}^{\circ} 1$, diciembre.

- (2011) "El retorno de un gigante", Le Monde Diplomatique, $\mathrm{n}^{\circ} 142$, abril.

- y R.B. Collier (2008), "Golpeados pero de pie: resurgimiento sindical y neocorporativismo segmentado en Argentina (2003-2007)", Politics and Society, vol. 35, $\mathrm{n}^{\circ}$ 3, Sage.

Ferrero, Juan Pablo y María Silvana Gurrera (2007), "El sindicalismo de movimiento social. Algunas reflexiones en torno del concepto", en Arturo Fernández (ed.), Estado y sindicatos en perspectiva latinoamericana, Buenos Aires: Prometeo.

Ghigliani, P. (2008), "La noción de derrota en la historia reciente del movimiento obrero argentino", Actas V Jornadas de Sociología de la UNLP, La Plata, 10, 11 y 12 de diciembre.

- y A. Belkin (2010), "Burocracia sindical: aportes para una discusión en ciernes", Nuevo Topo, ${ }^{\circ} 7$.

Hyman, Richard (1981), Relaciones industriales: una introducción marxista [1975], Madrid: Hermann Blume.

Iñigo Carrera, N. (2009), "Indicadores para la periodización (momentos de ascenso y descenso) en la lucha de la clase obrera: la huelga general. Argentina, 1992-2002", Documento de trabajo 72, PIMSA, Buenos Aires.

Levitsky, Steven (2005), La transformación del justicialismo. Del partido sindical al partido clientelista, 1983-1999, Buenos Aires: Siglo XXI.

Maiello, M. y E. Albamonte (2016), "Gramsci, Trotsky y la democracia capitalista”, Estrategia Internacional, n ${ }^{\circ} 29$.

Mandel, E. (1994), El poder y el dinero, México: Siglo Veintiuno.

Murillo, María Victoria (1997), "La adaptación del sindicalismo argentino a las reformas de mercado en la primera presidencia de Menem", Desarrollo Económico, vol. XXXVIII, $\mathrm{n}^{\circ} 147$, octubre-diciembre.

Piva, A. (2006), "El desacople entre los ciclos del conflicto obrero y la acción de las cúpulas sindicales en Argentina (1989-2001)", Estudios del Trabajo, $\mathrm{n}^{\circ} 51$.

Rakovsky, C. (1928), "Los peligros profesionales del poder", disponible en https://www.marxists.org/espanol/rakovski/1928/08-1928.htm.

Santella, A. (2014), "Qué son los sindicatos en la teoría marxista", Archivos de Historia del Movimiento Obrero y la Izquierda, año III, $\mathrm{n}^{\circ} 5$, septiembre.

Scodeller, G. y P. Ghigliani (2010), "La burocracia sindical: del concepto a la historia. Entrevista con Nicolás Iñigo Carrera", Nuevo Topo, $\mathrm{n}^{\circ} 7$.

Senén González, C. y J. Haidar (2009), "Los debates acerca de la "revita- 
lización sindical" y su aplicación en el análisis sectorial en Argentina", Revista Latinoamericana de Estudios del Trabajo, $2^{a}$ época, $\mathrm{n}^{\circ} 22$.

Senén González, C. y A. Del Bono (2013), "Introducción", en La revitalización sindical en Argentina: alcances y perspectivas, C. Senén González y A. Del Bono (comps.), Buenos Aires: Universidad Nacional de La MatanzaPrometeo.

Torre, Juan Carlos (2004), El gigante invertebrado. Los sindicatos en el gobierno, Argentina 1973-1976, Buenos Aires: Siglo XXI.

Trotsky, L. (2010), "Los sindicatos en la época de la decadencia imperialista”, en Los sindicatos y las tareas de los revolucionarios, Buenos Aires: IPS-CEIP "León Trotsky".

Varela, P. (2013), "Los sindicatos en la Argentina kirchnerista: entre la herencia de los 90 y la emergencia de un nuevo sindicalismo de base", Archivos de Historia del Movimiento Obrero y la Izquierda, año I, $\mathrm{n}^{\circ} 2$.

- (2014), "De los conflictos del crecimiento a los conflictos de la crisis. Hipótesis sobre la dinámica de la conflictividad en la última década", VIII Jornadas de Sociologia de la UNLP, diciembre, La Plata.

- (2015a), La disputa por la dignidad obrera. Sindicalismo de base fabril en la zona norte del Conurbano bonaerense, 2003-2014, Buenos Aires: Imago Mundi-Colección Archivos.

- (2015b), "La estrategia objetiva. ¿Ilusión teleológica del historiador?”, Archivos de Historia del Movimiento Obrero y la Izquierda, año III, $\mathrm{n}^{\circ} 6$, marzo.

Vasallo, D. (2015), "Suspensiones a la carta”, Ideas de Izquierda, n 20, junio.

$$
* * *
$$

Titulo: The policeman on the threshold: approaches and debates on trade union bureaucracy in the kirchnerismo

Resumen: El fortalecimiento de los sindicatos durante el kirchnerismo ha sido objeto de múltiples estudios e interpretaciones centrados, mayoritariamente, en el análisis de los cambios en la negociación colectiva, la conflictividad laboral, la organización en el lugar de trabajo o el denominado "modelo sindical". Fue entre estos temas que se entremezcló el problema de la burocracia sindical como un objeto incómodo cuya forma de ser pensado resulta indisociable de las particularidades del "retorno" del movimiento obrero a la escena política nacional: con la fuerza suficiente como para echar por tierra las teorias del fin del trabajo (y sus colaterales), pero con la debilidad suficiente como para no poder imponer la pregunta sobre la clase obrera como sujeto politico.

En este artículo presentamos críticamente tres perspectivas desde las que ha sido abordado el problema de la burocracia sindical durante el kirchnerismo no sólo porque ellas implican miradas teóricas distintas, sino también porque permiten comprender algunas particularidades del período.

Palabras clave: Burocracia sindical - Peronismo - Revitalización sindical - Kirchnerismo - Marxismo 


\begin{abstract}
Union revitalization during Kirchner administration has been the subject of many studies. Most of them have focused in the analysis of changes in collective bargaining, labor unrest, the organization in the workplace or the so-called "union model". It was among these issues, the problem of the union bureaucracy intruded as an uncomfortable object whose way of being thought is inextricably linked to the peculiarities of the "return" of the labor movement to the national political scene: with enough force to displace theories of the end of labor, but weak enough to not be able to impose the question on the working class as a political subject.

This article deals, in a critical way, with three perspectives from which it has been addressed the problem of the union bureaucracy during the kirchnerismo not only because they imply different theoretical perspectives, but also because they allow us to understand some peculiarities of the period.
\end{abstract}

Key words: Union bureaucracy - Peronism - Union revitalization - Kirchnerismo - Marxism

Recepción: 5 de febrero de 2016. Aprobación: 20 de marzo de 2016. 